\title{
THE CONTAGION EFFECT IN EUROPE: A DCC GARH APPROACH
}

\author{
Paulo Alexandre ${ }^{1}$ \\ Paula Heliodoro ${ }^{2}$ \\ Rui Dias ${ }^{3}$
}

DOI: https://doi.org/10.31410/LIMEN.2019.73

\begin{abstract}
This research analyses the co-movements between sovereign debt markets, and the stock markets of Germany, Portugal, and Greece, in the period 2009:10 - 2015:07. It aims to provide answers to two questions, namely, whether: i) Was there contagion between bond markets and the Eurozone stock markets? ii) Did the financial sector show contagion? The study used GARCH-DCC econometric models, with the purpose of estimating the dynamic correlation between the markets, using daily data of 10-year OT yields for Greece and Portugal, as well as price indices for Portugal (PSI-20, PSI Financial), and Germany (DAX-30 and DAX Financial). In addition, we also evaluate the variation of the correlation in each of the identified crisis periods against a reference period (pre-crisis). The results suggest contagion from the Greek sovereign debt market to the Portuguese and German stock markets. We found that the Portuguese debt market influenced the German stock market, in a market and financial sector context. In conclusion, it is assumed that the results reveal some understanding of the behaviour of investors under extreme market conditions and contribute to the understanding of the connection between sovereign risk and financial sector risk by market agents, including regulators and policy-makers, who seek to ensure the stability of the international financial system, of which the stock markets are a part of.
\end{abstract}

Keywords: Financial contagion, Stock market, Euro sovereign debt crisis, GARCH-DCC.

\section{INTRODUCTION}

$\mathrm{T}$ his study aims to investigate the possible occurrence of contagion during the European sovereign debt crisis in the stock markets of some Euro Zone (EA) countries and, in particular, the shares of companies in the financial sector, attempting to determine whether the contagion to this specific sector, was in any case more significant than the potential contagion in the stock market as a whole.

The creation of the EA has further increased financial integration among the countries participating in the Monetary Union (MU), therefore contributing to increased financial stability through the creation of larger, more liquid and competitive markets, which offer greater possibilities of risk diversification and lower transaction costs, which ultimately have a positive impact on each country's economic growth potential. However, in a scenario such as the sovereign debt crisis, stronger financial integration results in higher risks/costs, not only for the countries directly affected but, apparently, for all others. This situation is caused by the potential existence of contagion effects between the various markets of the various countries, which cause shocks specific to some specific countries to spread throughout the EA (Gonzalez-Paramo 2011).

\footnotetext{
1 Polytechnic Institute of Setúbal, School of Business and Administration, Esce, Campus do Instituto Politécnico de Setúbal, Estefanilha, 2914-503 Setúbal, Portugal

2 Polytechnic Institute of Setúbal, School of Business and Administration, Esce, Campus do Instituto Politécnico de Setúbal, Estefanilha, 2914-503 Setúbal, Portugal

3 Polytechnic Institute of Setúbal, School of Business and Administration, Esce, Campus do Instituto Politécnico de Setúbal, Estefanilha, 2914-503 Setúbal, Portugal
} 
This research has two main goals. The first is to investigate the existence of contagion from one country's bond market to another country's bond market in the context of the sovereign debt crisis. The second purpose is to check the occurrence of contagion, specifically among the shares of the companies that make up the financial sector, in order to determine whether the contagion effect to this specific sector is higher than that verified in the stock market as a whole. This study also makes it possible to evaluate whether the impact of the debt crisis on equity markets is variable according to the sovereign risk of the country of the market itself, considering that the equity markets of countries with different risk classes, namely Portugal and Germany, are analyzed.

The results suggest the existence of contagion from the Greek sovereign debt market to the stock markets of Portugal and Germany, both for the stock market as a whole and more specifically for the stocks of the companies that make up the financial sector, in most of the periods of crisis identified. There also has been evidence of contagion to the German stock market from the Portuguese sovereign debt market, although on a smaller scale than in the case of Greek sovereign debt. The hypothesis that there is a higher contagion effect on the stocks of financial sector companies than on the stock market as a whole is not supported by the results obtained in any of the analyses.

This study aims to contribute to the literature essentially in two aspects. Firstly, it analyses the existence of contagion between markets of different asset classes, not in the same country, but in different countries of the EA, focusing on contagion in stock markets. This analysis is made in a context of the sovereign debt crisis, combining the GARCH-DCC methodology with the identification of several periods of crisis in the sovereign debt securities market. Secondly, it explores the relationship between sovereign risk and financial sector risk in the EA, through a study of contagion specific to this sector, seeking to determine whether the market value of companies belonging to the financial sector were strongly affected in comparison to the rest of the market as a whole.

In terms of structure, this paper is organised into 5 sections. In Section 2 we present a review of the literature on contagion in financial markets. Section 3 describes the methodology. Section 4 contains the data and results. Section 5 sets out the conclusion.

\section{LITERATURE REVIEW}

The sovereign debt crisis in the EA has motivated several studies related to the topic of financial contagion among the various UM countries, with special focus on the contagion of Greece to other countries. For obvious reasons, one of the most debated aspects in the literature has been the contagion between sovereign debt markets during this period. In addition, the existence of studies that prove the occurrence of contagion in the sovereign debt markets of the EA countries, supports in some aspects the possibility of the transmission of shocks also to the stock markets (Alexakis and Pappas, 2018; Finta, Frijns, and Tourani-Rad, 2019; Antonakakis, Gabauer, and Gupta, 2019; Golab and Zamojska, 2019; Pentecost et al., 2019).

Tola and Wälti (2015) and Gómez-Puig and Sosvilla-Rivero (2016) have demonstrated the existence of contagion in sovereign debt markets during the sovereign debt crisis. Tola and Wälti (2015) test the existence of contagion in the sovereign debt markets of nine SAP countries during the sovereign debt crisis. The authors demonstrate the occurrence of contagion on a large scale between the bond markets of the countries analysed during the sovereign debt crisis, 
with around three quarters of the country-specific shocks resulting in contagion to other UM countries. Nevertheless, asymmetric contagion was also detected in some cases, a situation that occurs when the shock felt in the debt market of a given country causes a movement contrary to the OT yield of some other country, namely, phenomena of „flight to quality”. Gómez-Puig and Sosvilla-Rivero (2016) indicate the existence of contagion during the initial phase of the euro crisis, namely from the Greek sovereign debt market to the sovereign debt markets of Portugal, Spain, Italy and Belgium, but not to the sovereign debt markets of Austria and the Netherlands.

More recently, Anastasopoulos (2018), Finta, Frijns, and Tourani-Rad (2019), Antonakakis, Gabauer, and Gupta (2019) and Pentecost et al. (2019) examined the effects of contagion between European and non-European markets in the context of the sovereign debt crisis. Anastasopoulos (2018) shows that the contagion effects of the Greek debt crisis were not persistent, while the effects of the depreciation of the yuan were. Finta, Frijns, and Tourani-Rad (2019) suggest the existence of two-way contagion between the stock markets. However, there is asymmetry and time variation in contagion, namely, the shocks from Germany to peripheral stock markets are larger than the opposite. Antonakakis, Gabauer, and Gupta (2019) suggest that Greek economic policy uncertainty is influencing European economic policy uncertainty approximately throughout the analysis period. Finally, the analysis of the response to shocks, suggests that the persistence of monetary policy shocks varies over time and has increased after the global financial crisis of 2007-2009. This magnifying effect partly explains the longer-term recovery of the European economy. Pentecost et al. (2019) found a different pattern of contagion coming from Ireland and compared with other markets such as Greece, Italy, Portugal and Spain. They examined the factors that made countries vulnerable to contagion and showed that financial factors are more important than those from trade.

\section{METHODOLOGY}

In this study, the first step in econometric analysis is to evaluate the time series stationarity. This analysis becomes essential since such characteristics are fundamental for the data generator process modelling (Lütkepohl and Krätzig 2004). The Augmented Dickey-Fuller test (Dickey and Fuller 1981) postulates that the null hypothesis is non-stationary or integrated of order $d(d>0)$, I (1), against the alternative hypothesis of stationarity (Said and Dickey 1984). To validate the ADF test, we use the KPSS test (Kwiatkowski et al. 1992), where the hypotheses presented are contrary to the ADF test, i.e. H_0 postulates that the series is I (0) against the alternative that the series are I (1) (Noman and Rahman 2010).

The methodology used to determine the occurrence of financial contagion from the sovereign debt market in Greece to the stock markets in Portugal and Germany, and from the sovereign debt market in Portugal to the German stock market, is based on the estimation of the dynamic conditional correlation between the changes in OT's yield and the yields of the stock index, using a GARCH-DCC (Generalized Autoregressive Conditional Heteroskedasticity - Dynamic Conditional Correlation) model. Once this correlation is determined, it is analysed how it evolves in each of the identified crisis periods (from the sovereign debt market) compared to a reference period (pre-crisis).

We consider that this approach is suitable because, in the view of this study, financial contagion is associated with the occurrence of excessive co-movements, i.e. to episodes of increased correlation between asset returns, which can therefore be identified. 
The model of dynamic conditional correlation (DCC-GARCH), suggested by Engle (2002) and Tse and Tsui (2002), is distinguished from other models, such as the constant conditional correlation proposed by Bollerslev (1990) in that the conditional correlation matrix changes over time.

In the DCC-GARCH model, the conditional covariance matrix is written as follows:

$$
\sum_{t}=D_{t} \Gamma_{t} D_{t}
$$

Where:

$$
\begin{aligned}
& D_{t}=\operatorname{diag}\left(\sqrt{h_{11, t}}, \sqrt{h_{22, t}}, \ldots, \sqrt{h_{n n, t}}\right. \\
& \Gamma_{t+1}=\left[\operatorname{diag}\left(Q_{t}\right)\right]^{-1 / 2} Q_{t}\left[\operatorname{diag}\left(Q_{t}\right)\right]^{-1 / 2} \\
& Q_{t}=(1-\alpha-\beta) \bar{Q}+\alpha U_{t-1} U_{t-1}^{\prime}+\beta Q_{t-1}
\end{aligned}
$$

\section{DATA AND RESULTS}

\subsection{Data}

The data used in this study to evaluate the occurrence of contagion from the sovereign debt markets of Greece and Portugal to the stock markets of the selected countries were extracted from the Thomson Reuters platform. For the sovereign debt markets, implicit interest rates, Treasury Bond yields (OT's) with 10-year maturity in Greece and Portugal are used.

To analyse possible contagion to the stock markets of Germany and Portugal, the reference indices for Germany and Portugal (DAX-30 and PSI-20) are taken into account. The DAX and PSI Financial indices are used to study the contagion specific to the shares of companies belonging to the German and Portuguese financial sectors, respectively, as they reflect exclusively the market value of companies in this sector (banks, insurance companies and various financial services) in these two countries. These data are of daily frequency and refer to the period between October 1, 2009 and July 13, 2015.

\subsection{Results}

This study was conducted with the objective of ascertaining the existence of contagion from the Greek sovereign debt market to the stock markets of Portugal and Germany, and from the Portuguese sovereign debt market to the German stock market, in the period between 1 October 2009 and 13 July 2015, namely to the stocks of the companies belonging to the financial sector, with the objective of determining whether the contagion effect to this specific sector was in any way stronger than that verified in the stock market as a whole.

The results suggest the existence of contagion from the sovereign debt market in Greece to the Portuguese stock market as a whole, since most of the periods of crisis identified in the Greek debt market gave rise to episodes of contagion to Portuguese shares (73\%). It was also ascertained, specifically, the existence of contagion from the Greek sovereign debt market to the shares of the companies that make up the financial sector of the Portuguese stock market, since most of the periods of crisis identified in the Greek debt market resulted in contagion episodes to these listed companies $(80 \%)$. 
However, considering that the number of contagion episodes in each of the analyses was very close, and the fact that the average decrease in the correlation (between OT yield changes and equity index yields) in these same episodes, relative to the reference periods, was slightly higher in the analysis of contagion to the whole stock market, it was not concluded that there was a higher contagion effect than those listed in the financial sector compared to the Portuguese stock market as a whole. In addition, the analysis suggests that the turbulent period associated with the $1^{\text {st }}$ international bailout of Greece (May 2010) and, more recently, the stalemate period preceding the principle of agreement leading to the $3^{\text {rd }}$ Greek bailout (June/July 2015) have caused apprehension among investors.

There was also evidence of contagion from the Greek sovereign debt market to the German stock market as a whole, as most of the periods of crisis identified in the Greek debt market resulted in episodes of contagion to German stocks (80\%). It was also found that contagion from the Greek sovereign debt market to the stocks of the companies that make up the financial sector of the German market, as most of the periods of crisis identified in the Greek debt market led to episodes of contagion to these listed companies (73\%). However, the results obtained do not support the existence of a stronger contagion effect on the shares of the financial sector in relation to the entire German stock market, given that both the number of contagion episodes ascertained and the average decrease in the correlation (between the changes in the OT's yield and the yields of the stock index) verified in these same episodes, in comparison to the reference periods, were higher in the analysis involving the entire German stock market.

In addition, as in the analysis of contagion of Greek debt to the Portuguese stock market, the research indicates that the $1^{\text {st }}$ international bailout of Greece (May 2010) and the negotiations that led to the principle of agreement of the $3^{\text {rd }}$ Greek bailout (June/July 2015) were the events in which there was a greater transmission of negative investor sentiment to German shares. It should also be noted that, in the case of the latter event, this transmission seems to have penalized most German stocks more than those listed in the financial sector.

The results suggest that investors do not seem to have made a distinction between the stock markets of Portugal and Germany according to the sovereign risk of each of the countries, and they have been affected in the same way in most of the periods of crisis identified in the Greek debt market, since they present a very similar number of contagion episodes.

The analysis involving the Portuguese sovereign debt market and the German stock market as a whole, also revealed contagion from the first to the second, as most of the periods of crisis identified in the Portuguese sovereign debt market, caused episodes of contagion to German shares $(60 \%)$. Similarly, the existence of contagion in the Portuguese sovereign debt market was specifically found to exist in the stocks of the companies belonging to the financial sector of the German Stock Exchange, considering that half of the periods of crisis identified in the Portuguese debt market caused contagion episodes to these listed companies (50\%).

However, given that the number of contagion episodes was higher in the analysis of contagion to the entire German stock market, and given that the average decrease in the correlation (between OT yield changes and stock index yields) in these same episodes, relative to the reference periods, was quite close in both analyses, the existence of a contagion effect higher than those listed in the financial sector relative to the German stock market as a whole was not determined. 
The analysis of contagion from the Greek and Portuguese sovereign debt markets to the German stock market indicates that the latter was more contagious to the evolution of the price of Greek sovereign debt securities than to the Portuguese, since both the (absolute) number of contagion episodes ascertained and the proportion of these to the total of crisis periods identified in each of these sovereign debt markets were higher in the analysis involving the Greek debt market. This is not surprising given that the Greek sovereign debt crisis has been more serious and more difficult to resolve than the other crises experienced by other euro area countries since 2010, namely the Portuguese and Irish ones, which presupposes a more significant contagion effect from the Greek debt market to the markets of the other euro countries. These results are in line with the evidence suggested by Beirne and Fratzscher (2013), Kenourgios (2014), Finta, Frijns, and Tourani-Rad (2019), Pentecost et al. (2019) which show contagion from the sovereign debt crisis.

\section{CONCLUSION}

In conclusion and based on the outcome of this investigation, we can notice the existence of contagion from the Greek sovereign debt market to the Portuguese and German stock markets and also, although on a smaller scale, from the Portuguese sovereign debt market to the German stock market, both to the market as a whole and specifically to companies listed in the financial sector. However, contrary to our expectations, in none of the cases analysed was solid evidence obtained that would determine the existence of a contagion effect greater than the shares of the companies comprising the financial sector, in relation to that verified in the stock market as a whole.

Considering the existence of contagion effects among the various countries of the EA, both between bond markets and between bond markets and shareholders, as this study demonstrates, when an UM country is affected by a crisis it puts at risk the financial stability of the others. Therefore, in an economic policy level, and in a scenario of imminent crisis, it is considered to be of extreme importance the immediate action of the Government of the affected country to obtain agreements with the international authorities that make it possible to contain and reduce the contagion to other countries, namely through economic and financial assistance programs. In addition, it is understood that the European institutions, together with the increasing financial integration among countries, will be expected to implement more and better trans-European control mechanisms that are effective and that make it possible to detect and resolve, in a timely manner, situations of imbalance, structural or conjunctural. This is important since requests for external assistance, on their own, will not solve the situation in the medium/long term, as exemplified by the three Greek bailouts in recent years.

\section{REFERENCES}

Anastasopoulos, Alexia. 2018. "Testing for Financial Contagion: New Evidence from the Greek Crisis and Yuan Devaluation." Research in International Business and Finance.

Antonakakis, Nikolaos, David Gabauer, and Rangan Gupta. 2019. "Greek Economic Policy Uncertainty: Does It Matter for Europe? Evidence from a Dynamic Connectedness Decomposition Approach." Physica A: Statistical Mechanics and its Applications.

Beirne, John, and Marcel Fratzscher. 2013. "The Pricing of Sovereign Risk and Contagion during the European Sovereign Debt Crisis." Journal of International Money and Finance.

Bollerslev, Tim. 1990. "Modelling the Coherence in Short-Run Nominal Exchange Rates: A Multivariate Generalized Arch Model." The Review of Economics and Statistics 72(3): 498. http://www.jstor.org/stable/2109358?origin=crossref. 
Dickey, David, and Wayne Fuller. 1981. "Likelihood Ratio Statistics for Autoregressive Time Series with a Unit Root." Econometrica 49(4): 1057-72.

Engle, Robert. 2002. "Dynamic Conditional Correlation.” Journal of Business \& Economic Statistics 20(3): 339-50. http://www.tandfonline.com/doi/abs/10.1198/073500102288618487.

Finta, Marinela Adriana, Bart Frijns, and Alireza Tourani-Rad. 2019. "Time-Varying Contemporaneous Spillovers during the European Debt Crisis.” Empirical Economics.

Gómez-Puig, Marta, and Simón Sosvilla-Rivero. 2016. "Causes and Hazards of the Euro Area Sovereign Debt Crisis: Pure and Fundamentals-Based Contagion." Economic Modelling.

Gonzalez-Paramo, Jose Manuel. 2011. "Sovereign Contagion in Europe." Economic and Financial Review 18(4): 152-66. http://www.eefclondon.org/pubs/efr.html\%5Cnhttp:// search.ebscohost.com/login.aspx?direct $=$ true $\& d b=$ ecn \&AN=1295568\&site=ehost-live \&scope $=$ site.

Kenourgios, Dimitris. 2014. "On Financial Contagion and Implied Market Volatility." International Review of Financial Analysis 34: 21-30. http://dx.doi.org/10.1016/j.irfa.2014.05.001.

Kwiatkowski, Denis, Peter C. B. Phillips, Peter Schmidt, and Yongcheol Shinb. 1992. "Testing the Null Hypothesis of Stationary against the Alternative of a Unit Root." Journal of econometrics 54(1): 159-78.

Lütkepohl, Helmut, and Markus Krätzig. 2004. Applied Time Series Econometrics Applied Time Series Econometrics.

Noman, Abdullah M, and M Zillur Rahman. 2010. "Stationarity of South Asian Real Exchange Rates Under Exponential Star (ESTAR) Framework." The Journal of Developing Areas 43(2): 41-50. http://muse.jhu.edu/journals/journal_of_developing_areas/v043/43.2.noman. html\%5Cnhttp://muse.jhu.edu/journals/journal_of_developing_areas/v043/43.2.noman. pdf.

Pentecost, Eric J., Wenti Du, Graham Bird, and Thomas Willett. 2019. "Contagion from the Crises in the Euro-Zone: Where, When and Why?" European Journal of Finance.

Said, Said E., and David A. Dickey. 1984. "Testing for Unit Roots in Autoregressive Moving Average Models of Unknown Order.” Biometrika 71(3): 599-607.

Tola, Albi, and Sébastien Wälti. 2015. "Deciphering Financial Contagion in the Euro Area during the Crisis." Quarterly Review of Economics and Finance 55: 108-23.

Tse, Y. K., and Albert K.C. Tsui. 2002. "A Multivariate Generalized Autoregressive Conditional Heteroscedasticity Model with Time-Varying Correlations." Journal of Business and Economic Statistics 20(3): 351-62. 